\title{
O PROCESSO DE INOVAÇÃO DE UMA EMPRESA DE SERVIÇOS GRÁFICOS PARA MERCADO CORPORATIVO PELA ANÁLISE DA TEORIA EFFECTUATION
}

Elisabete Fernandes ${ }^{1}$

Alexandre Nabil Ghobril ${ }^{2}$

${ }^{1}$ CCSA / CCSA / Universidade Presbiteriana Mackenzie

${ }^{2}$ Universidade Mackenzie 


\section{O PROCESSO DE INOVAÇÃO DE UMA EMPRESA DE SERVIÇOS GRÁFICOS PARA MERCADO CORPORATIVO PELA ANÁLISE DA TEORIA EFFECTUATION}

\section{Resumo:}

Os serviços digitais têm progressivamente substituído a produção tradicional do setor gráfico. O desafio das empresas do setor tem sido reestruturar o portfólio de oferta de modo a se modernizarem e atenderem às demandas e exigências crescentes de seus clientes. Este artigo analisa o processo decisório do empreendedor, que encontra respaldo na teoria do effectuation, ao apresentar as bases de seu comportamento influenciado principalmente por feeling, laços pessoais e minimização de riscos. Para apresentar a trajetória percorrida pelo empreendedor em seu processo de análise e decisão seguiu-se o protocolo de relato tecnológico de Marcondes, Miguel, Franklin e Perez (2017). Diferentes ferramentas foram utilizadas para realizar o levantamento diagnóstico e análise das oportunidades e proposta de solução. Apesar das ferramentas de análise apresentadas ao empreendedor, pode-se identificar que seu processo de decisão diante de algumas alternativas analisadas, foi direcionado por sua percepção pessoal de aproveitar a oportunidade identificada de atender à solicitação de um parceiro comercial, com uma solução sob demanda.

Palavras-chave: inovação, novos produtos, gestão de pequenas empresas, integração de tecnologias, teoria do effectuation, empreendedorismo.

\section{Introdução}

A Graphis (nome fictício, para preservar os dados da empresa) é uma empresa que atua principalmente com locação e venda de equipamentos de impressão e de suprimentos de informática e serviços de controle de eventos gerados pela utilização de equipamentos. A empresa está sediada na cidade de Sumaré, região de Campinas - SP, estabeleceu-se inicialmente com um capital de $\mathrm{R} \$ 4$ mil reais, oriundos da venda de um carro, e com um sonho de ser empreendedor. A ideia surgiu através de um anúncio, em um programa de TV, de uma máquina que realizava recargas de cartuchos. Seu fundador, com experiência em vendas na área de papel e formação superior em química, com uma rápida e desastrosa experiência com marketing de rede, viu ali um caminho para iniciar seu próprio negócio. Sem a elaboração de um plano de negócios estruturado, análise para a aquisição de recursos e uma execução deliberada do plano de negócios (TASIC 2002), ele abriu a empresa em 2007, com a proposta de atender ao nicho de mercado de recarga de cartuchos para pessoas físicas (B2C - Business to Consumer) e, consequentemente, clientes foram solicitando a manutenção de impressoras. Os clientes foram surgindo de forma orgânica, sem um processo estabelecido de prospecção e venda de produtos e equipamentos, migrando em 2009, para atendimento a empresas (B2B Business to Business), adicionando ao seu portfólio a venda de suprimentos originais e locação 
A empresa de turismo CVC da cidade de Sumaré, já cliente na compra de suprimentos, foi primeira a contratar o serviço de locação e, ainda hoje, é cliente da Graphis.

Com demanda crescente, o serviço de locação de equipamentos de impressão foi sendo ampliado. Todavia, alguns serviços foram acordados sem a devida formalização contratual, o que potencialmente gera problemas futuros, por falta de clareza dos direitos e deveres das partes.

Esse fato, que de certa forma ocorre com muitas empresas no estágio de toca-toca ou adolescência - de acordo com as fases identificadas no modelo do ciclo de vida das organizações de Adizes (Adizes, 2004) -, é caracterizado por uma maior preocupação com vendas e faturamento do que com controle, gestão de pessoas e análise de risco.

A Graphis enfrentou, ainda, outros problemas típicos de uma empresa nesse ciclo de pouca maturidade, como a falta de critérios objetivos para contratação de funcionários, muitas vezes realizada por indicação e coleguismo, sem a devida avaliação de competências técnicas e comportamentais necessárias para a execução da função.

Em 2014 buscando alternativas para a redução de receita, oriundas da perda de um dos seus maiores clientes, a Graphis investiu na ampliação do espaço físico e especializou-se na manutenção de impressoras e recargas de toners a empresa.

No ano seguinte, inovou no service desk por meio da implantação do monitoramento remoto da utilização dos equipamentos do cliente, chamado MPS (monitoramento contínuo dos processos de impressão). Com isso, agregou valor ao serviço, minimizando desperdícios pelo controle do fluxo de suprimentos e funcionamento do equipamento.

Apesar de atuar em um mercado bastante grande em números absolutos, a empresa percebe que o setor tem passado por grandes transformações nos últimos tempos, com tendência de redução do volume de vendas de equipamentos e aumento da competição com grandes players, na venda de suprimentos de informática. Além disso, seus competidores no segmento de locação de equipamentos vêm atuando cada vez mais de forma digital, aprimorando os serviços ofertados aos clientes.

Além disso, a empresa otimizou a organização de dados e segurança das informações e virtualização dos processos administrativos com a contratação de um servidor próprio, o que permitiu um gerenciamento efetivo dos processos internos e possibilitou o acesso remoto aos dados e informações dos clientes quando a equipe está em campo, agilizando o acesso aos eventos dos equipamentos e possibilitando mais rapidez em retornar com informações solicitadas pelos clientes, como, por exemplo, falhas no equipamento.

Neste ano (2018), a Graphis conta com 90 clientes de locação de equipamentos de impressão e em torno de 450 clientes para a venda de produtos da área de suprimentos de informática, venda e manutenção dos equipamentos. Além disso, a empresa fechou um contrato de locação de equipamentos de impressão e sistema de gerenciamento de impressões com a rede supermercados SuperPreço (nome fictício usado para preservar a identidade da empresa), atendendo a um grande número de lojas dessa rede, e com potencial de ampliação do atendimento, para abranger todo o grupo, que hoje corresponde a 29 pontos de venda. 


\section{Referencial Teórico}

De acordo com Marcondes, Miguel, Franklin e Perez (2017), a pesquisa aplicada tem a finalidade de servir de base para que os gestores da empresa possam tomar decisões eficazes sobre novos negócios, mercados, estratégias, estruturas, parcerias, ou seja, tudo o que possa trazer os melhores resultados para ajudá-los a aumentar a competitividade da organização, visando obter um desempenho superior ao dos seus concorrentes. E, para tal, antes de qualquer análise e proposição, é essencial que se faça um bom diagnóstico.

Neste trabalho, para desenvolver o diagnóstico, optou-se inicialmente por uma abordagem exploratória que contemplou as seguintes ações complementares: a) contato inicial com o empreendedor, visita in loco às instalações da empresa e entendimento de sua história, estrutura, processos e produtos; b) entrevista em profundidade com o empreendedor para compreensão da sua percepção de problemas e oportunidades do negócio; c) entrevista com os funcionários para compreensão das atividades desenvolvidas; d) acesso a dados da empresa e informações complementares.

De acordo com Ludke e André (1986), essa abordagem metodológica, de caráter exploratório, é adequada para esse tipo de situação, quando se objetiva explorar a variável de estudo tal como se apresenta e seu significado no contexto em que ela se insere.

Para a entrevista em profundidade, foi preparado um roteiro semiestruturado, com o objetivo de obter informações mais completas sobre o modelo de gestão, estrutura, processos, além de principais problemas enfrentados, oportunidades vislumbradas e desafios futuros.

Uma vez conhecidos os processos organizacionais e o portfólio de produtos, e considerando analisar alternativas estratégicas para o crescimento da empresa, entendeu-se que era fundamental também analisar a evolução dos resultados nos últimos períodos. Para isso, foi necessário acrescentar a coleta de dados quantitativos. Para tanto, o empreendedor disponibilizou planilhas com as informações solicitadas, com dados dos últimos exercícios.

Esse levantamento de dados foi seguido por uma análise de mercado, na qual se avaliou a oferta dos concorrentes locais e regionais, principalmente aqueles com negócios correlatos a segmento de locação e venda de equipamentos de impressão, área de maior crescimento da empresa nos últimos tempos.

\section{Oportunidade definida}

O empreendedor entende que o atual momento de transformação no ambiente de negócios, onde a dinâmica da gestão precisa ser conduzida de forma mais criativa e inovadora, valendo-se das inovações tecnológicas que se traduzem em uma mudança no ambiente competitivo, precisa traduzir-se em estratégias dentro da própria empresa. 
Considerando ainda a base de clientes da empresa e sua reputação e acesso a eles, o empreendedor percebe uma oportunidade para a Graphis explorar no seu mercado de atuação outras formas de serviços e está ciente de que, para isso, precisará avaliar seu portfólio de produtos e serviços, como também ampliar a atuação para nichos de mercados não explorados.

Em função disso, a empresa tem buscado aproximar-se mais de alguns de seus principais clientes para entender melhor suas necessidades em diferentes níveis - comunicação, documentação, estoque e logística -, o que precisa ser traduzido em ofertas que agreguem valor efetivo que será entregue a eles.

Outra questão fundamental é o crescimento e ampliação, na região, das empresas de varejo, criando mais possibilidades de ampliar a carteira de clientes.

$\mathrm{Na}$ figura abaixo, apresentamos algumas possibilidades de oportunidades de produtos e/ou serviços no mercado, analisadas com base nos produtos ofertados pelos concorrentes diretos, apresentadas resumidamente, no quadro a seguir:

Figura 1 - Análise para desenvolvimento de oportunidades

\begin{tabular}{|c|c|c|c|}
\hline ONDE & $\begin{array}{c}\text { Análise } \\
\text { Oportunidade } \\
\text { Atuação } \\
\text { mercado } \\
\text { Concorrentes } \\
\end{array}$ & $\begin{array}{c}\text { Quem } \\
\begin{array}{c}\text { Segmento } \\
\text { clientes }\end{array}\end{array}$ & $\begin{array}{l}\text { Como } \\
\text { Ação no Portfólio } \\
\text { Produtos/serviços } \\
\end{array}$ \\
\hline Segmentos substitutos & $\begin{array}{l}\text { Cartazeamento } \\
\text { eletrônico }\end{array}$ & $\begin{array}{l}\text { Agrega valor às MPE* de } \\
\text { varejo no controle e } \\
\text { comunicação PDV (ponto } \\
\text { de venda) }\end{array}$ & $\begin{array}{c}\text { Desenvolvimento e implantação } \\
\text { de software de gestão }\end{array}$ \\
\hline $\begin{array}{l}\text { Na cadeia de } \\
\text { compradores }\end{array}$ & Plataforma cartaz pronto & Mercadinhos e Lojas Pets & $\begin{array}{l}\text { Assinatura/cartazeamento } \\
\text { eletrônico }\end{array}$ \\
\hline $\begin{array}{l}\text { Produtos e serviços } \\
\text { complementares }\end{array}$ & $\begin{array}{l}\text { Ampliação dos serviços } \\
\text { de TI-Cloud }\end{array}$ & MPE* em geral & $\begin{array}{l}\text { Processos de controle estoque } \\
\text { por meio eletrônico }\end{array}$ \\
\hline $\begin{array}{ll}\begin{array}{l}\text { Outros } \\
\text { estratégicos }\end{array} & \text { grupos } \\
\end{array}$ & $\begin{array}{l}\text { Plataforma de compras } \\
\text { online }\end{array}$ & MPE* em geral & $\begin{array}{l}\text { Estruturar plataforma } \\
\text { compras eletrônico }\end{array}$ \\
\hline
\end{tabular}

Fonte: Elaborada pela autora (2018). *Micro e pequenas empresas

O supermercado SuperPreço apresentou uma demanda de ampliação dos serviços de criação de cartazes promocionais e de integração desse processo com seus sistemas gerenciais. Isso abriu uma janela de oportunidade de parceria para a criação de um novo serviço que segue exatamente a tendência do mercado, qual seja, a oferta de serviços integrados a novas mídias digitais e conectados aos clientes.

As mudanças tecnológicas e o acesso dos clientes aos meios digitais imprimem nas pequenas empresas uma forte necessidade de dinamizar os processos administrativos e, consequentemente, trazem uma redução de custos proporcionada pela informatização. Ao 
digitalizar o processo de divulgação de ofertas e promoções no ambiente interno e externo das lojas, permite-se que as empresas atendam às expectativas de seus clientes com uma melhor identidade visual e clareza nas informações, bem como a otimização do processo de execução do trabalho, hoje realizado manualmente na maioria das empresas, e que demanda a contratação de profissional especializado para executá-lo, seja ele temporário ou efetivo (CLT). Segundo Luiz Carli:

Uma das principais vantagens que o cartazeamento eletrônico pode trazer é a comunicação uniforme, pois permite a padronização da comunicação do ponto de venda, sendo especialmente interessante no caso de redes de lojas. Com ele, o consumidor terá uma única percepção visual ao visitar qualquer unidade do grupo, transmitindo uma mensagem uniforme ao consumidor, não havendo variação de padrão de fontes e da forma de comunicação de loja para loja (Carli, 2018).

O sistema de cartazeamento eletrônico, pode ser gerenciado por uma plataforma digital, totalmente interligada ou por um sistema semi-integrado. No sistema semi-integrado não há a existência de um software de gerenciamento de dados. A gerência ou setor responsável, aciona o colaborador responsável pela impressão de cartazes e envia planilha com produtos préselecionados que serão ofertados, conforme política de ofertas da empresa. Em empresas que não tem nenhum sistema de controle, as informações de ofertas de produtos, são simplesmente adicionadas, em planilhas ou outros diferentes arquivos de gestão e impressas em papel sulfite nos formatos $\mathrm{A} 3$ ou $\mathrm{A} 4$ ou nos tamanhos adequados as necessidades e espaços disponíveis para a inserção da comunicação. O sistema integrado é o processo mais dinâmico e eficiente de gerenciamento de divulgação e controle dos estoques dos produtos divulgados, garantindo a padronização da comunicação. Bem como, os controles de gestão de fluxo das mercadorias, desde o estoque até a finalização da venda no caixa. Hoje, grandes redes de varejo estão migrando para integração direta em televisores instalados nos pontos de vendas internos, por exemplo, área de laticínios, carnes e panificação.

A Graphis, então, propôs à rede supermercados SuperPreço um projeto piloto de cartazeamento eletrônico mais integrado que, de um lado, lhe permite, alavancar um outro segmento de negócios alinhado com aquilo que o empreendedor entende ser o futuro da organização e exigirá pouco investimento em equipamentos, pessoas e estrutura adicional para viabilizar a entrega de um serviço digital e integrado aos sistemas do cliente. Por outro lado, esse projeto piloto permitirá ao cliente integrar e modernizar a comunicação visual interna e externa, em todas as lojas de sua rede.

Poderemos consolidar com a parceria para este projeto, a estratégia de desenvolver e comercializar no mercado regional o cartazeamento eletrônico, estruturando a equipe de vendas e desenvolvendo estratégias de marketing dentro do contexto do mercado alvo. No cenário econômico, as pequenas empresas necessitam inserir seus processos no ambiente tecnológico, visando reduzir custos e atender consumidores cada vez mais conectados.

O sistema de cartazeamento eletrônico atenderá, futuramente, essas pequenas empresas de varejo que, ainda utilizam o cartazeamento manual. A Garphis investirá na modernização do atendimento do portfólio de produtos - locação e suprimentos através de uma plataforma mais moderna e amigável, processo de reestruturação do departamento de vendas, ambos os 
processos em andamento - agilizando os procedimentos internos e a dinâmica de relacionamento com os clientes.

\section{A escolha do projeto sob a luz da teoria do effectuation}

A lógica de criação de empresas enfatizada no modelo de effectuation, desenvolvido por Saras Sarasvathy (2001) vem discutindo a forma como o empreendedor se organiza na estruturação dos negócios.

Até recentemente, procedimentos e atitudes padronizadas eram primordiais para o sucesso do negócio e o empreendedor planejava cada detalhe do futuro negócio, levando em conta um horizonte de muitos anos. A ferramenta mais empregada era o plano de negócio tradicional e as estratégias eram delineadas em um horizonte de 3 a 5 anos (Drucker, 1959). Porém, no cenário atual, a forma como as empresas são criadas é muito diferente das condições encontradas anteriormente. Hoje, o empreendedor precisa gerenciar de forma mais dinâmica, criativa e inovadora, dado o contexto das novas tecnologias, tornando o processo mais incerto, assim como os objetivos determinados (Cherubin, 2002).

Segundo Sarasvathy (2001), os modelos clássicos de decisão consideram um determinado efeito como dado e se concentram na seleção de meios (causas) que possam produzir os efeitos desejados. O modelo effectuation de decisão considera um conjunto de meios (causa) como dados e se concentra na seleção (escolha) entre possíveis efeitos que podem ser criados com aquele conjunto de meios.

O fluxo apresentado a seguir é descrito no passo a passo dos quatro princípios do estudo da teoria do effectuation: o que se tem, perdas aceitáveis, alianças estratégicas, exploração de contingências (figura 2).

Figura 2 - Ciclo de ação do empreendedor

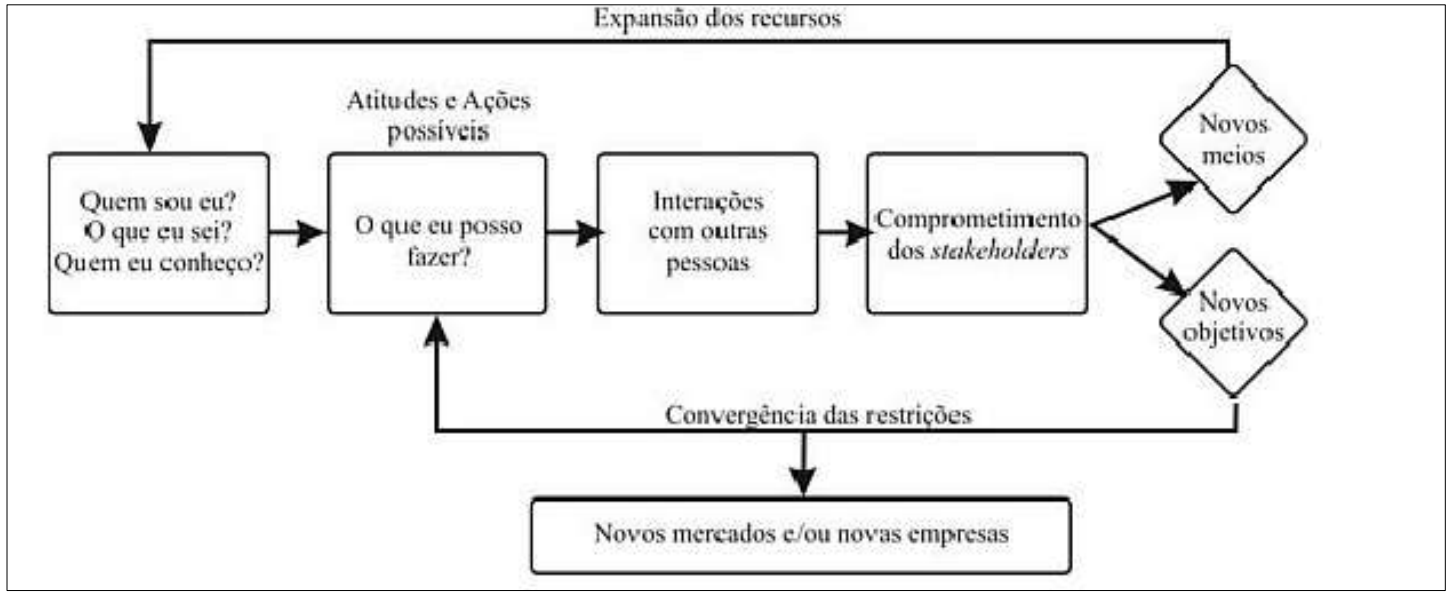

Fonte:

Adaptado de Read e Sarasvathy, 2005, p. 53. 
Pela lógica effectual, durante o processo decisório os empreendedores avaliam quanto eles suportam perder, experimentam diferentes estratégias e utilizam combinações dos recursos disponíveis. Nesta abordagem, propõe-se que o propósito do negócio seja diminuir as incertezas e riscos de certas estratégias, e não necessariamente, maximizar os retornos financeiros potenciais (Sarasvathys, 2001a). No processo de effectuation, o empreendedor precisa responder três perguntas (Sarasvathys, 2001b): (a) Quem ele é: quais são seus gostos, suas habilidades e suas competências; (b) $\mathrm{O}$ que ele sabe: qual a sua formação, educação e experiência; (c) Quem ele conhece: quais as suas redes sociais e profissionais. A partir desses três aspectos, os empreendedores começam a visualizar e desenvolver possíveis efeitos que podem ser criados com estas informações. De acordo com a lógica do effectuation, o empreendedor faz parte do contexto em que suas decisões são tomadas; dessa forma, ele não é independente, ele é parte de um ambiente dinâmico, envolvendo múltiplas decisões (Sarasvathy, 2001b). Desta forma, é uma ferramenta para a resolução de problemas quando o futuro é imprevisível, os objetivos não são muito claros ou são amplos, e quando o ambiente não é independente das decisões (Sarasvathy, 2004). Conforme descrito pela lógica do effectuation, o empreendedor tem papel principal na criação do negócio, que envolve múltiplas decisões, interdependentes e simultâneas. Mas, essa ação não é planejada, segundo avalia Sarasvathy (2001), de forma coerente e estruturada, defendendo, essa autora, a ideia de que esse processo não é linear. O modelo effectual é definido em quatro princípios destacados no contexto da empresa estudada.

No tocante à identificação do empreendedor, as oportunidades acessíveis são identificadas a partir de recursos existentes: sua identidade, seu conhecimento, suas redes de relacionamento, sobre os quais o empreendedor pode agir imediatamente. Os empreendedores começam por quem eles são, pelo que eles conhecem e quem eles conhecem, de forma a imaginar coisas que eles comecem pelo que tem. Isso reflete uma ênfase em eventos futuros que eles podem controlar, ao invés de prever (Sarasvathy, 2008). Isso pode ser identificado no empreendedor da Graphis, que acessou o seu cliente mais próximo e propôs uma possibilidade de testar um novo produto num cenário de incerteza, quanto a um novo mercado e uma nova tecnologia, e uma parceria para promover as validações necessárias para a criação desse produto.

No que diz respeito às perdas aceitáveis, o empreendedor determina algum nível de perda e experimenta tantas estratégias quantas possíveis, dada a limitada reserva de recursos disponíveis. Ao analisar, a lógica effectual pela proposta da Graphis, e ao discutir esse cenário, houve o entendimento do empreendedor sobre a fragilidade do seu atual modelo de negócio. Analisar os diferentes cenários, munido de informações relevantes do setor, das tendências sociais, tecnológicas e econômicas, e dos ambientes micro e macro, formará um arcabouço relevante para formular um Plano de Ação, em um processo mais linear, que promova o desenvolvimento e a sustentabilidade do negócio, buscando através de informações externas ao negócio, dados que apoiem e estruturem a formulação da estratégia. Toda a análise realizada leva à seguinte direção: a empresa precisa oferecer produtos e serviços mais digitais, utilizando as tecnologias já disponíveis.

Em relação a este ponto, há um cenário altamente competitivo das empresas que atuam no segmento de locação e os eventos decorrentes desta oferta de serviços. A Graphis enfrentará 
competição e precisará de soluções mais inovadoras, que tragam uma proposta de valor reconhecida pelo mercado.

No estudo que fizemos, outro comportamento se alinha no tocante às alianças estratégicas e pré-comprometimentos com parceiros como forma de reduzir ou eliminar incertezas, verificase outro princípio da lógica effectuation aplicada ao caso da Graphis, aproveitando o ótimo relacionamento com os clientes locais, em detrimento do alcance que os meios eletrônicos viabilizam. O valor do contato direto e a rede de relacionamentos dos negócios locais são diferenciais a serem inicialmente considerados pela empresa, confirmando os aspectos descritos por Sarasvathy (2008), de forma que a oportunidade para ampliar o portfólio de produtos e ou serviços da empresa, vá se ajustando aos objetivos. Assim, esses stakeholders vão, por meio de frequentes negociações e renegociações, modelando a proposta. Alguns produtos explorados pelos concorrentes, como locação de coletores e leitores de dados (como por exemplo leitura de código de barras), cartazeamento eletrônico, plataforma de comércio eletrônico e consultoria de tecnologia, foram analisados para possível introdução no portfólio da empresa.

Ao analisar as possibilidades de produtos e serviços apresentadas pelo mercado e as demandas dos clientes, a Graphis verificou um nicho de negócio digital que seria um diferencial da empresa a ser ofertado ao seu maior cliente, representado por 29 lojas na região, que utiliza o serviço de locação de equipamentos para a impressão de etiquetas de preços. Dessa forma, há a proposta desse parceiro de comprometer recursos para viabilizar o projeto, que define dois ciclos de desenvolvimento de uma nova proposta de serviços: formação de um novo modelo de negócios e um novo mercado: (1) um ciclo expansivo que aumenta os recursos disponíveis, diminuindo os riscos e (2) um conjunto convergente de restrições sobre os objetivos da rede de parceiros (Sarasvathy, 2008).

O cartazeamento eletrônico é um diferencial para a melhoria da comunicação com o cliente e dá mais visibilidade nas ações de promoção. Em lojas que utilizam cartazeamento manual, minimizará custos gerados por erros de escrita e pela utilização de um funcionário especializado para sua execução.

Foi proposto iniciar um projeto piloto nas quatro novas lojas do cliente SuperPreço, migrando a impressão para cartazeamento eletrônico de etiquetas e banners de comunicação de preços e promoções. Com a parceria desse cliente no projeto piloto, há uma grande oportunidade de minimizar os riscos e promover a validação técnica da solução, aproveitando-se do momento de crescimento da rede, implantando nas novas lojas uma comunicação interna e externa mais amigável e de qualidade gráfica inovadora.

Cabe aqui, novamente, uma reflexão crítica com relação ao fato de existir, atualmente, uma grande dependência da Graphis (40\% do seu faturamento) em relação à rede supermercados SuperPreço. Apesar de ser uma relação comercial antiga e de confiança, essa aposta de desenvolvimento do projeto aumentaria ainda mais, em um primeiro momento, a concentração das vendas na rede de supermercados em questão. Qual é o risco associado a essa empreitada?

De fato, esse tema é controverso. Uma corrente da literatura advoga que a concentração da base de clientes aumenta o risco operacional das empresas (Dhaliwal, Judd, Serfling e Shaikh, 2016). A perda de um grande cliente pode prejudicar os negócios e a condição financeira da empresa e até levá-la à falência. Por outro lado, empresas que têm intenso relacionamento com grandes 
clientes podem reduzir custos de marketing e transação, resultando em um melhor desempenho, ficando, entretanto, em posição de certa fragilidade e de menor poder de barganha na negociação de preços com o cliente (Patatoukas, 2012).

Irvine, Park e Yildizhan (2016) mostram que a relação entre concentração e lucratividade baseadas no cliente é uma função do ciclo de vida do relacionamento: isso é significativamente negativo nos primeiros anos do relacionamento, mas se torna positivo quando o relacionamento amadurece.

Sob essa perspectiva, a exploração de contingências, embora seja sabido que a alta concentração de vendas em um único cliente traga alguns riscos, neste caso a ponderação é que as vantagens superam os riscos no curto prazo. Mas é certo que a Graphis precisará buscar ampliar e diversificar sua carteira no médio prazo, ajustando seu modelo de negócios e criando outros serviços inovadores.

\section{Ganhos com a solução}

O projeto está permitindo, além do lançamento de uma linha de serviços ao mercado, o desenvolvimento de competências técnicas, com o desenvolvimento do software de gestão realizado por desenvolvedor contratado pela Graphis e com a implementação do serviço de cartazeamento eletrônico em curso nas quatro novas lojas da rede.

Essa oportunidade permite testar o novo produto, com baixo risco de insucesso para a Graphis, mesmo que a princípio não apresente alta lucratividade. $\mathrm{O}$ acordo comercial prevê a ampliação do serviço, alcançando as demais 25 lojas da rede supermercados SuperPreço. Na negociação, a rede de supermercados optou por assumir a gestão desse serviço, e destacou dois funcionários, exclusivamente, para realizar a administração e distribuição nas lojas de todo o material impresso. Em contrapartida, a Graphis fornecerá todo o suprimento (lonas e toners) e a atualização do software, de acordo com as necessidades que surgirão e que poderão ser agregadas ao sistema, gerando melhoria de processo e o controle adequado de recursos.

A Graphis dá continuidade ao contrato com a comunicação interna das lojas (impressão em folhas A3 ou A4) e etiquetas de gôndola, hoje representando, em média, 1.800 impressões/dia (cartazes), num total de 52.200 impressões/mês. Nessa continuidade de prestação de serviços, inclui-se a manutenção do contrato com a atualização do software e sistema de monitoramento pelo sistema de gestão de eventos da Graphis (MPS), atualização do parque de equipamentos de impressão disponibilizados no sistema de locação e continuidade do fornecimento de suprimentos e manutenção dos equipamentos próprios.

Ocorreu um incremento no faturamento da Graphis em 2018, em torno de R $\$ 220$ mil, somente com os novos serviços à rede supermercados SuperPreço. Considerando manter um valor diferenciado para este cliente, e aumentar o faturamento com mais soluções que poderão ser agregadas ao sistema, como por exemplo o sistema de cartazeamento digital (terminais de televisão). 
Após a validação da solução de cartazeamento eletrônico por meio do projeto piloto implantado no cliente SuperPreço, a Graphis pretende ampliar a oferta do serviço para diferentes clientes, inclusive aqueles de menor porte.

Tendo a análise realizada confirmado a adequabilidade e o interesse da Graphis em avançar com o projeto piloto de implantação do cartazeamento eletrônico junto à rede supermercados SuperPreço, a etapa seguinte objetiva aprofundar a análise sobre a forma e viabilidade de transformar esse serviço em um novo segmento de negócio da empresa.

O segundo passo iniciou-se no segundo semestre de 2018. Após negociações e a proposta de a empresa SuperPreço ser parceira no projeto, a Graphis antecipou a compra de uma impressora plotter no valor de R \$ 40 mil para a validação do cartazeamento eletrônico no cliente.

Realizadas todas as fases de regularização do sistema de controle do processo de cartazeamento, a rede supermercados SuperPreço adquiriu o equipamento (máquina plotter) e, sob a responsabilidade de dois funcionários, realiza a gestão de todas as impressões de banners para as 29 lojas da rede. A gestão desse serviço foi estruturada pela Graphis, que criou o sistema (software) que efetua o controle de utilização e realiza a venda de toners e dos rolos de lona para impressão dos banners.

Além de economia, a empresa cliente ganhará agilidade na gestão das ofertas, já que o sistema integra as informações entre o departamento de marketing e o financeiro. O sistema armazena as informações sobre os produtos que entraram em promoção e gerencia a repetição das ofertas, sinalizando eventuais ofertas já disponibilizadas anteriormente. Isso proporciona maior controle de material impresso e o reaproveitamento do banner em ofertas futuras, melhora a qualidade da comunicação nas 29 lojas e minimiza a ocorrência de erros gramaticais nos cartazes.

Para a Graphis, a implantação do processo de cartazeamento eletrônico é a possibilidade de controlar um futuro imprevisível ao invés de prever um futuro incerto (Sarasvathy, 2001 e 2008), com potencial de expandir o atendimento a esse parceiro, que está em crescimento e demandará a aquisição de outros serviços da Graphis.

Com isso, o empreendedor vislumbrou a possibilidade de captação de novos clientes, ancorado na experiência do acompanhamento e entendimento das necessidades do supermercado SuperPreço.

Reflexo disso é que o projeto já alavancou outras iniciativas derivadas, como a oferta de uma plataforma com pacotes de serviços de cartazeamento empacotados e que já está em desenvolvimento. A nova oportunidade, propiciada pelo domínio da tecnologia do projeto piloto com a rede supermercados SuperPreço, é voltada a empresas de menor porte e com menos recursos para investir. Para esse mercado, está em análise um modelo de negócio completamente diferente, de cauda longa, onde os clientes poderão criar seus próprios cartazes a partir de modelos semiprontos e recebê-los impressos (modelo SAS - software as service), mediante uma assinatura mensal (tabela 1). 
Tabela 1 - Síntese do ciclo de ação do empreendedor aplicado na Graphis

\begin{tabular}{|c|c|c|c|c|}
\hline \multicolumn{5}{|c|}{ Contexto da realidade mais competitiva do mercado } \\
\hline $\begin{array}{l}\text { Quem Eu sou? } \\
\text { O Que Sei } \\
\text { fazer? Quem } \\
\text { Conheço? } \\
\quad \text { Meios } \\
\text { Experiência setor }\end{array}$ & $\begin{array}{l}\text { O que posso fazer } \\
\text { com os meios } \\
\text { disponíveis } \\
\text { Introduzir no } \\
\text { portfólio da } \\
\text { empresa um novo } \\
\text { produto }\end{array}$ & $\begin{array}{l}\text { Interações } \\
\text { Parceiros } \\
\\
\text { Rede } \\
\text { supermerca } \\
\text { dos } \\
\text { SuperPreço }\end{array}$ & $\begin{array}{l}\text { Conhecimento/Valida } \\
\text { ção do cartazeamento } \\
\text { eletrônico }\end{array}$ & $\begin{array}{l}\text { Contexto mais favorável } \\
\qquad \text { Novos Meios } \\
\text { Ampliar serviço para todas as } \\
\text { lojas da rede supermercados } \\
\text { SuperPreço }\end{array}$ \\
\hline Estrutura enxuta & \multicolumn{4}{|c|}{$\begin{array}{l}\text { Decisões acerca dos novos mercados e/ou novas empresas para o cartazeamento } \\
\text { eletrônico }\end{array}$} \\
\hline $\begin{array}{l}\text { Confiança } \\
\text { clientes } \\
\text { Rede clientes }\end{array}$ & $\begin{array}{l}\text { O que posso fazer } \\
\text { com os meios } \\
\text { disponíveis } \\
\text { Abranger outros } \\
\text { ramos de } \\
\text { atividades }\end{array}$ & $\begin{array}{l}\text { Interações } \\
\text { Parceiros } \\
\text { Pequenos } \\
\text { varejistas de } \\
\text { diferentes } \\
\text { segmentos }\end{array}$ & $\begin{array}{l}\text { Comprometimento } \\
\text { Buscando parcerias }\end{array}$ & $\begin{array}{l}\text { Contexto mais favorável } \\
\text { Novos Meios } \\
\text { - Digitalização processos } \\
\text { controles gerenciais } \\
\text { - Opção de ofertar venda } \\
\text { cartazes via assinatura }\end{array}$ \\
\hline
\end{tabular}

Fonte: Elaborada pela autora (2018).

\section{Considerações finais e contribuições}

Este trabalho apresenta o relato do processo de análise, decisão e implementação de uma nova solução em serviços de cartazeamento eletrônico da empresa Graphis para o mercado corporativo.

O trabalho seguiu o protocolo de relato tecnológico de Marcondes, Miguel, Franklin e Perez (2017), iniciando-se pela avaliação do atual cenário do setor gráfico, pela observação das tendências tecnológicas e do ambiente competitivo. Ficou evidenciado que as empresas do setor precisarão fazer a transição para novas mídias, entender o funcionamento destas, adotá-las e ajustá-las ao seu modelo de negócio, tornando-se mais flexíveis, mais sustentáveis, digitais e conectadas às necessidades dos clientes. 
Em seguida, foi realizado um diagnóstico da empresa Graphis, que contemplou visita in loco às instalações, análise de processos e produtos; entrevista com o empreendedor e acesso a relatórios e dados operacionais e financeiros.

Seguiu-se a análise das oportunidades. A matriz BCG permitiu um melhor entendimento do portfólio atual de oferta da Graphis e sinalizou a necessidade de criação de novos produtos que venham a substituir os produtos atualmente geradores de caixa, mas com tendência a se tornarem obsoletos. Utilizou-se em seguida a SWOT, para maior robustez da análise estratégica e escolha de soluções que congreguem as forças da empresa e seu potencial de mercado.

Tal análise permitiu a identificação de algumas oportunidades de criação e oferta de novos serviços com potencial de negócio alinhados às necessidades dos clientes em diferentes níveis: comunicação, documentação, estoque e logística. A solução escolhida foi a criação de um projeto de cartazeamento eletrônico que propicia aos clientes mais agilidade, qualidade e visibilidade na criação de cartazes promocionais da cadeia varejista.

Foi iniciado um projeto piloto em quatro novas lojas da rede supermercados SuperPreço, seu principal cliente. A solução, alinhada com a estratégia da Graphis, mitiga riscos de investimentos e de validação técnica do projeto, visto que o cliente investiu recursos próprios para adquirir máquinas e equipamentos de impressão de grande porte requeridos pelo projeto, e que a demanda encomendada garantiu uma receita recorrente já no início do projeto.

Finalmente, analisou-se o processo de decisão do empreendedor à luz da teoria do effectuation. Pode-se identificar que, apesar de o diagnóstico e a análise apresentados pela pesquisadora ao empreendedor terem contribuído para sua visão de futuro da organização, a opção pelo projeto de cartazeamento eletrônico não foi, de fato, estruturada com base na análise técnica comparativa das alternativas existentes.

A decisão foi calcada principalmente na percepção de uma oportunidade que surgiu do bom relacionamento e de uma necessidade premente de seu principal cliente. Foi baseada em princípios como confiança, aliança estratégica, exploração de contingências favoráveis e limitação de perdas e de risco, o que está de acordo e pode ser explicado pelo modelo effectual.

A análise do processo de diagnóstico e de busca da solução da Graphis mostrou que soluções inovadoras surgiram da conexão mais intensa com clientes pela busca de solução para seus problemas cotidianos, e pela disponibilidade de estar ao lado deles para encontrarem juntos a solução, e também pela visão de negócio e sensibilidade do empreendedor para identificar a oportunidade.

No caso em estudo, avaliamos que, além do desenvolvimento de um novo serviço, a oportunidade foi ampliada pela incorporação de tecnologia à solução, como o desenvolvimento do software para dar suporte ao projeto em parceria com empresa de Tecnologia da Informação (TI), criando, de fato, uma inovação que chega ao mercado. No segundo momento, esta parceria foi incorporada ao negócio, com a contratação do desenvolvedor. Desta forma, a inteligência aplicada ao desenvolvimento do produto foi integrada aos processos da Graphis.

Apesar da complexidade do processo, do tempo de negociação, do esforço para identificação e seleção de fornecedores, das idas e vindas para ajustar a solução, entendemos que o ganho vai 
além da receita e lucros potenciais do projeto, estendendo-se para o desenvolvimento de competência interna e reputação.

Além disso, o projeto oportuniza o desenvolvimento de negócios relacionados, como a oferta de uma plataforma com pacotes de serviços de cartazeamento voltado a pequenas empresas, por meio de um modelo de negócio de SAS - software as service

A percepção das dificuldades iniciais do empreendedor, suas limitações financeiras, de estrutura, e de recursos são aspectos descritos pela lógica effectual e reconhecidamente vivenciados neste período de trabalho junto à empresa Graphis. Foi possível perceber os atalhos e os caminhos do empreendedor em busca de oportunidades, a importância de seu capital social, seu processo decisório orientado por visão de futuro, que acreditamos t.er ajudado a desenhar, reforçando algumas premissas da teoria do effectuation, como a crença do empreendedor na sua intuição, nas parcerias, na minimização de riscos, o que reflete diferentes caminhos e possibilidades de construção de empresas. Destacamos neste período, a importância do estudo de referencial teórico embasando a construção do texto e consolidando as ações práticas aplicadas na empresa Graphis.

Por fim, avaliamos que o crescimento e o futuro da empresa dependerão não somente do aproveitamento das oportunidades para criação e oferta de novos serviços, mas também da competência da gestão e execução da estratégia, o que demandará investimentos em capacitação e profissionalização de equipe, além de busca de recursos e parcerias que deem sustentação ao negócio a longo prazo.

\section{Referências bibliográficas}

Abell, D. F. (1993). Managing with Dual Strategies. Mastering the present. Preempting the future. New York: Free Press. Pearson.

Adizes, Ichak. (2004). Gerenciando os ciclos de vida das organizações. São Paulo:

Carli, L. (2018, 26 de março) Cartazeamento eletrônico no varejo: dicas, benefícios e cuidados na implantação. Recuperado em 20 de novembro de 2018, de https://www.maxpress.com.br/Conteudo/1,942416,Cartazeamento_eletronico_no_varejo_dica s_beneficios_e_cuidados_na_implantacao_-_Por_Luiz_Carli_,942416,4.htm

Carli, L. (2012, maio) White Paper - 7 Dicas para eficiência em outsourcing de impressão Recuperado em 15 de maio de 2018, de http://docplayer.com.br/2646443-7-dicaspara-eficiencia-em-outsourcing-de-impressao.html\#show_full_text.

Computerworld. (2017, 28 de abril). Vendas de impressoras no Brasil têm queda de 29\% em 2016. Recuperado em 10 de maio de 2018, de http://computerworld.com.br/vendas-deimpressoras-no-brasil-tem-queda-de-29-em-2016 
Computerworld. (2016, 24 de maio). O mercado de PCs ainda dá lucro? Gartner afirma que sim. Recuperado em 15 de maio de 2018, de http://computerworld.com.br/o-mercado-depcs-ainda-da-lucro-gartner-afirma-que-sim

Costa, H. T. (2015, novembro). Qual o futuro da gráfica?. Revista Abigraf (250). Recuperado em 10 de maio de 2018, de https://issuu.com/abigraf/docs/revista_abigraf_250

Costa, R. L. da. (2012). Estratégia organizacional e "outsourcing”. Os recursos estratégicos de competitividade empresarial. São Paulo: Almedina.

Dhaliwal, D., Judd, S., Serfling, M., \& Shaikh, S. (2016), Customer concentration risk and the cost of equity capital, Journal of Accounting and Economics, 61 (1), pp. 23-48.

FecomercioSP. Pesquisa Conjuntural do Comércio Varejista no Estado de São Paulo. $\begin{array}{llllll}\text { Recuperado em } 10 \text { de } & \text { maio de }\end{array}$ http://www.fecomercio.com.br/busca?termos=Pesquisa+Conjuntural+do+Com\%C3\%A9rcio+ Varejista+no+Estado $+\mathrm{de}+\mathrm{S} \% \mathrm{C} 3 \% \mathrm{~A} 3 \mathrm{o}+$ Paulo\&filtro $=\& \mathrm{ano}=\& \mathrm{mes}=$

Fundação Seade. Pesquisa de Investimentos realizada em 2017. Recuperado em 13 de maio de 2018, de http://www.piesp.seade.gov.br/\#m-regiao

GEM [Global Entrepreneurship Monitor]. (2010). Empreendedorismo no Brasil: 2009. Curitiba: Instituto Brasileiro da Qualidade e Produtividade. Recuperado em 10 de maio de 2018, de https://www.gemconsortium.org.

Hall Jr., E. H. (1995). Corporate diversification and performance: an investigation of causality, Australian Journal of Management, 20 (1), pp. 1-18, June 1995.

Henderson, B. Matriz BCG. Recuperado em 10 de abril de 2018, de https://pt.wikipedia.org/wiki/Matriz_BCG

Hirata, Giselle. (2016, 22 de maio). Fundada por ex-caixeiro viajante, Kalunga é destaque em São Paulo. Folha de S.Paulo. Recuperado em 10 de junho de 2018, de http://www1.folha.uol.com.br/saopaulo/2016/05/1773354-fundada-por-ex-caixeiro-viajantekalunga-e-destaque-em-sao-paulo.shtml

Hitt, M. A., Ireland, D. R., \& Hoskisson, R. E. (2003). Administração estratégica. 1.ed. São Paulo: Pioneira/Thompson Learning.

IDC Brasil. (2017, 28 de abril). Mercado de impressoras tem queda de 29\% em 2016, afirma IDC. Recuperado em 10 de maio de 2018, de https://inforchannel.com.br/2017/04/28/mercado-de-impressoras-tem-queda-de-29-em-2016afirma-idel

Inforchannel. (2017, 13 de abril). 3 dicas de processos que otimizarão a impressão dentro das empresas. Recuperado em 23 de maio de 2018, de https://inforchannel.com.br/2017/04/13/3-dicas-de-processos-que-otimizarao-impressaodentro-das-empresas/

Irvine, P., Park, S., \& Yildizhan, C. (2016), Customer-based concentration, profitability, and the relationship life cycle, The Accounting Review, 91 (3), pp. 883-906. 
Johnson, M. W., Kagermann, H., \& Christensen, C. M. (2015, 27 de maio). Reinvente seu modelo de negócios. Harvard Business Review. Recuperado em 10 de maio de 2018, de http://hbrbr.uol.com.br/reinvente-seu-modelo-de-negocios/

Ludke, M., \& André, M. E. D. A. (1986). Pesquisa em educação: abordagens qualitativas. $1^{\text {a }}$ ed. São Paulo: EPU.

Marcondes, R. C., Miguel, L. A. P., Franklin, M. A., \& Perez, G. (2017). Metodologia para elaboração de trabalhos práticos e aplicados em administração e contabilidade. São Paulo: Mackenzie, CCSA.

Marzochi, R. (2016, 16 de dezembro). O futuro tridimensional da HP. IstoÉ Dinheiro. Recuperado em 25 de maio de 2018, de https://www.istoedinheiro.com.br/noticias/mercadodigital/20161216/futuro-tridimensional/442926

Menezes, D. N. (2014). Análise dos custos de outsourcing de serviços de impressão. Centro Universitário Metodista Izabela Hendrix. Apresentado no IX Saepro. Universidade Federal de Viçosa. Recuperado em 2 de maio de 2018, de http://www.saepro.ufv.br/wpcontent/uploads/2014.6.pdf.

MTE/RAIS. (2016). 9mil gráficas concentram-se região sudeste. Revista Abigraf. Recuperado em 10 de maio de 2018, de http://www.abigraf.org.br/anuario-brasileiro-daindustria-grafica

Osterwalder, A., \& Pig, Y. (2011). Business model generation: inovação em modelos de negócios. Rio de Janeiro: Alta Books.

Patatoukas, P. (2012). Customer-base concentration: implications for firm performance and capital markets, The Accounting Review, 87(2), pp. 363-392.

Read, S.; Sarasvathy,S. (2005). Knowing What to Do and Doing What You Know Effectuation as a Form of Entrepreneurial Expertise. The Journal of Private Equity,v. 9, n. 1, p. 45-62, DOI:10.3905/jpe.2005.605370.

Ries, E. (2012). A startup enxuta. (C. Szlak, Trad.). São Paulo: Leya.

Rodríguez, M. J. P. (1998). Problemas vinculados con la diversificación empresarial: la medición de la estrategia de la empresa. Cuadernos de Estudios Empresariales, n. 8.

Sarasvathy, S. D. (2001a). Causation and Effectuation: Towards at Theoretical shift from economic inevitability to entrepreneurial contingency. Academy of Management Review, v 26(2), April, 2001, pp. 243-288.

Sarasvathy, S. D. (2001b). Effectual reasoning inentrepreneurial decision making: Existence and bounds. Best paper proceedings, AcademyofManagement, Washington, pp. 3-8.

Sarasvathy, S. D. (2001c). What Makes Entrepreneurs Entrepreneurial? School of Business, University of Washington, pp.1-9.

Sarasvathy, S. D. (2008). Effectuation: Elements of Entrepreneurial Expertise. Cheltenham: Edward Elgar Publishing Limited, 2008. 
SEBRAE. http://www.sebrae.com.br/sites/PortalSebrae/artigos/voce-ja-tem-o-planode-acao-do-seu-negocio,d005844b68257510VgnVCM1000004c00210aRCRD. Recuperado em 09 de maio de 2018.

SEBRAE.http://www.sebrae.com.br/sites/PortalSebrae/estudos_pesquisas/fatorescondicionantes-e-taxas-de-mortalidade-das-mpe-nos-estadosdetalhe25, f893cdbc74834410VgnVCM1000003b74010aRCRD. Recuperado em 20 de maio de 2018.

Singh, M., Mathur, I., Gleason, K. C. \& Etebari, A. (2001). An empirical examination of the trend and performance implications of business diversification. The Journal of Business and Economic Studies, 7 (2), pp. 25-80.

Varajão, J. E. Q. A. S. (2002). Contributos para a melhoria do sucesso da adopção de tecnologias de informação e desenvolvimento de sistemas de informação nas organizações. (Dissertação de doutoramento). Departamento de Sistemas de Informação da Universidade do Minho, Guimarães, Portugal. Recuperado em 10 de maio de 2018, de http://repositorium.sdum.uminho.pt/bitstream/1822/25960/1/TesePhdJoaoVarajao.pdf

Zukunftsinstitut (2016). Mega Trends Glossar. Recuperado em 13 de junho de 2018, de https://www.zukunftsinstitut.de/artikel/mtglossar/ 